\title{
The Effect of Sugar Fortification with Vitamin A on Serum Retinol and Retinol Binding Protein of Khalwa Students at Risk of Vitamin A Deficiency SAM Shommo, AM Alamin, FY Zumrawi and AM Saeed.
}

\begin{abstract}
Background: Vitamin A deficiency (VAD) is a public health problem in Sudan

Objectives: The aim of this study is to test the effect of sugar fortified with vitamin A on VA status of Khalwa students (informal education).

Methods:Sixty Khalwa students age 6-11 years were included in the study. Each student consumed about $28 \mathrm{~g}$ of the fortified sugar for thirty days. Blood samples were collected before breakfast, to measure serum retinol (SR) and retinol-binding protein (RBP) of children before and after consuming the fortified sugar. Data including socioeconomic status and dietary intake of VA rich food were obtained. Anthropometric measurements and clinical examinations to detect signs of VAD were performed.
\end{abstract}

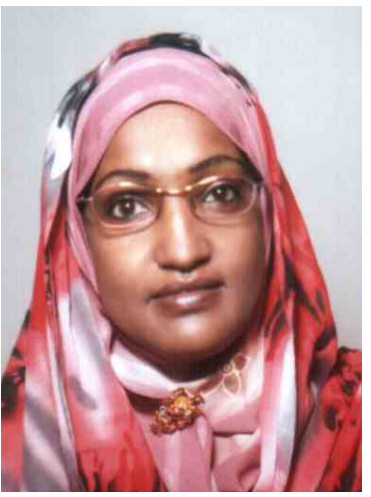

Results: Mean SR was $32.42 \pm 15.43 \mathrm{ig} / \mathrm{dl}$ and mean RBP was $20.96 \pm 14.32 \mathrm{mg} / \mathrm{l}$, which increased significantly to $49.08 \pm 12.2 \mathrm{ig} / \mathrm{dl}$ and $30.42 \pm 15.95 \mathrm{mg} / \mathrm{l}$ respectively after consumption of the fortified sugar $(\mathrm{P}=0.000$ for $\mathrm{SR}$ and $p<0.005$ for $\mathrm{RBP})$. Serum retinol 30 days response (SR30DR) and retinol binding protein 30 days response (RBP30DR) both showed levels indicating severe $\mathrm{VAD}$ as a public health problem at baseline among $60 \%$. Most cases were from low socio-economic status and $43.3 \%$ were mildly malnourished.

Conclusion: sugar fortification improved SR and RBP of the studied subjects who were considered at risk of VAD and would be expected to reduce the prevalence of VAD in Sudan.

Key words: Africa, malnutrition, measles.

$\mathrm{V}$ itamin A deficiency is one of the leading causes of child mortality in sub-Saharan Africa. The percentage of preschool children who were at risk of vitamin A deficiency was $42 \%$. By controlling vitamin A deficiency, deaths of 650,000 children can be prevented every year. ${ }^{1}$

Sudan is classified as one of the least developed countries with manifestation of food deprivation ${ }^{2}$. It is one of the 26 countries where vitamin A deficiency, xerophthalmia, and night blindness are considered as public health problems ${ }^{3}$. In 1999, the prevalence of night-blindness was estimated to be between $0.01 \%-1 \%{ }^{4}$. In 2004, vitamin A deficiency problem in Sudan was identified to be in the category of clinical according to WHO

Home science dept. Faculty of Education, University of Khartoum.P.O.Box 3028 Khartoum, Sudan; and Physiology dept., Faculty of Medicine, University of Khartoum.
Eastern Mediterranean Region categorization of VAD as public health problem ${ }^{5}$. The most recent survey in Sudan in 2005 reported that there were 99 informal schools, which are known as "Khalwas". The number of students studying in these Khalwas was 10,752 students. These students were at risk of VAD and the incidence of night blindness among them was $0.9 \%{ }^{6}$.

The use of vitamin-A-fortified foods contributes significantly to dietary intake and improves vitamin A status of at-risk populations. An evaluation of the mandatory national sugar fortification program in Honduras showed that it was an effective intervention ${ }^{7,8}$.

Countries such as Zambia have implemented sugar fortification, but the programs are too new to be evaluated for its effectiveness. Kenya and South Africa were also considering the development of sugar fortification program ${ }^{9}$.

This study was conducted on a group at risk 
of VAD to assess the effect of introducing sugar fortified with vitamin $\mathrm{A}$ in the form of retinol palmitate on their vitamin A nutritional status. Assessment was based on measuring vitamin A status prior to and after consumption of the fortified sugar for 30 days.

This study will enable us to determine whether vitamin A deficiency is a problem among Khalwa students and to introduce a practical method to eradicate this problem.

\section{Materials and Methods:}

The study included 60 students aged 6-11 years from rural and urban Khalwas. The first rural group was 24 students, from a Khalwa in Jabal Awlia Province, Khartoum State and the second was an urban group of 36 students, from a Khalwa in Western Omdurman Province, Khartoum State. Of these 30 resident students were included. Those who have been supplemented with capsules within the last six months were excluded.

Fortification of sugar was performed with vitamin A as retinol palmitate. The dose was designed according to the daily recommended dietary allowances (RDA) issued by $\mathrm{WHO}^{10}$. The RDA for the subjects within the age group 6-11 is $300-575 \mu \mathrm{g} /$ day as retinol ${ }^{11}$.

The Subjects:

All students were interviewed by a questionnaire, which included dietary and socioeconomic data. Anthropometric measurements and clinical examinations were done.

Weight for height Z-score was used to classify the nutritional status into: normal $(>-$ $1)$, mild $(-1--2)$, moderate $(-2--3)$, and severe $(<-3)$ with reference to the criteria of $\mathrm{WHO}^{12}$. Clinical examination to detect signs of VAD was done.

Biochemical analysis:

This was done for thirty subjects who agreed to give blood samples. Five milliliters of fasting blood samples were collected. Blood was allowed to clot and serum was pipetted into 2 epindorf tubes closed tightly and stored at $-20 C^{\circ}$ till time of analysis of SR and RBP.

SR was determined using HPLC (Bieri et al, 1979) ${ }^{13}$. Radial immunodiffusion method was used for determination of $\mathrm{RBP}^{14}$.

A second blood sample was collected after consumption of the fortified sugar for one month. SR and RBP were reevaluated to determine the percentage increase and their 30 Days Response (30DR) which was reported to be a more sensitive indicator of inadequate vitamin A status than only estimating serum level of vitamin A when blood levels were above $20 \mu \mathrm{g} / \mathrm{dl}^{15}, 16$. A cut-off point of $20 \%$ increase within 30 days was used to identify a deficient level at baseline and the effectiveness of the fortified sugar ${ }^{17}$.

Data were analyzed using SPSS Analysis of variances for quantitative data at $95 \%$ confidence interval $(P \leq 0.05)$.

\section{Results}

Most of the subjects were malnourished with low weight for height Z-score. Only 15\% were found to be normal while $43.3 \%$ had mild malnutrition. Moderate malnutritional status was found in $30 \%$ of the Khalwa students, and severe malnutrition was observed in $11.7 \%$.

The frequency of vitamin A rich food intake was assessed. Results have shown that the percentages of students who "always" consume green/yellow vegetables and fruits, red meat/liver, and egg were $16.7 \%, 18.3 \%$, and 5\% respectively (Figure 1).

\section{Fig.1:Frequency of vitamin A Rich Food Intake}

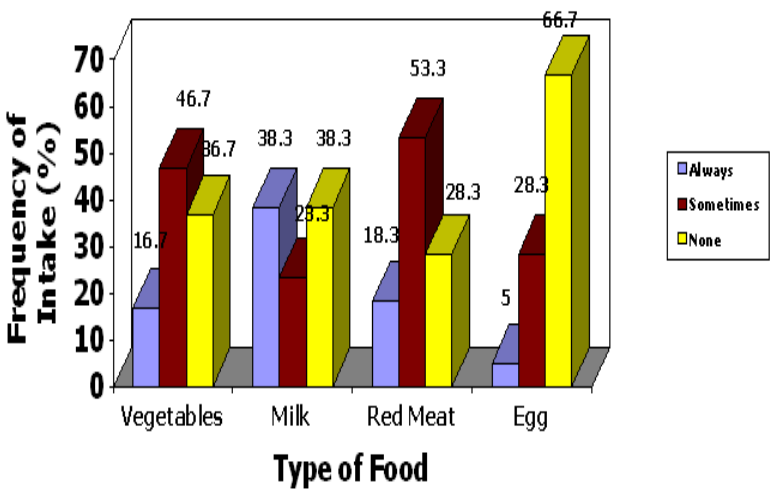

Low socioeconomic status was seen in $49.3 \%$ where all children showed signs of VAD whereas $16.7 \%$ had high status.

Out of 11 students who had infection, eight were found to have VAD. A percentage of $18.3 \%$ of the total subjects suffered from infectious diseases mainly malaria and upper respiratory tract infections. Signs of VAD were detected in $72.2 \%$ of those who were infected. 
In our study group clinical signs of VAD were detected in $51.7 \%$ of the students. These signs were within grades 1-5 according to the WHO clinical classification of vitamin A deficiency ${ }^{18}$.

Most of the students had an adequate level of SR (76.7\%). Marginal level was recorded among $20.0 \%$, whereas only one student was deficient. Mean serum retinol before supplementation was $32.42- \pm 15.43 \mu \mathrm{g} / \mathrm{dl}$, which increased to a mean of $49.1 \pm 12.2 \mu \mathrm{g} / \mathrm{dl}$ after consumption of fortified sugar.

The mean of RBP before and after sugar consumption were $20.96 \pm 15.43 \mathrm{mg} / \mathrm{l}$ and 28.8 $\pm 15.9543 \mathrm{mg} / \mathrm{l}$ respectively. No student had a high level of RBP, however, $6.6 \%$ changed to high after consumption. Similar percentage of students had low and medium levels (46.7\%); whereas, two students proved to be deficient (Table 1).

Table 1: RBP Levels Before and After Sugar Consumption.

\begin{tabular}{c|cc|cc} 
Classification & \multicolumn{2}{|c|}{ RBPI } & \multicolumn{2}{c}{ RBPII } \\
& No. & \% & No. & \% \\
\hline Deficient & 2 & 6.6 & - & - \\
Low & 14 & 46.7 & 8 & 26.7 \\
Medium & 14 & 46.7 & 20 & 66.7 \\
High & 0 & 0 & 2 & 6.6 \\
Total & $\mathbf{3 0}$ & $\mathbf{1 0 0}$ & $\mathbf{3 0}$ & $\mathbf{1 0 0}$ \\
\hline
\end{tabular}

Table 2 shows the students 30 days response to the introduction of sugar fortified with VA regarding SR and RBP levels. Both SR30DR and RBP30DR have shown levels indicating severe deficiency among $60 \%$ of the subjects. The SR30DR showed that equal percentage of students $(20 \%)$ had moderate and mild VAD. RBP30DR indicated moderate VAD level in $13.3 \%$ of the students, and mild VAD in $26.7 \%$.

\section{Discussion}

Malnutrition with low weight for height Zscore was found in most of the subjects. Only $15 \%$ were found to be normal.

This high prevalence of malnutrition was attributed mainly to the type and mode of nutrition in the Khalwa. Khalwa diet is composed of porridge made of millet called (Dibliba) taken with soup made of dried okra (Bamia or Weka), some oil, and onions. These students spent most of their time in the Khalwa depending on this diet which is very poor in its V A contents ${ }^{19}$.

Table 2: Serum Retinol and Retinol Binding Protein 30 days Response (S30DR).

\begin{tabular}{|c|c|c|c|c|}
\hline \multirow{2}{*}{$\begin{array}{c}\text { Level of } \\
\text { importance } \\
\text { as a public } \\
\text { health } \\
\text { problem }\end{array}$} & \multicolumn{2}{|c|}{ SR30DR } & \multicolumn{2}{|c|}{ RBP30DR } \\
\hline & No. & $\%$ & No. & $\%$ \\
\hline Mild & 6 & 20.0 & 8 & 26.7 \\
\hline Moderate & 6 & 20.0 & 4 & 13.3 \\
\hline Severe & 18 & 60.0 & 18 & 60.0 \\
\hline Total & 30 & 100 & 30 & 100 \\
\hline
\end{tabular}

The mean time they spent in the Khalwa was $9.6 \pm 6.7$ months.

Our finding showed that the intake of vitamin A rich food is not very frequent and this might explain Khalwa students' vulnerability to the risk of VAD. This result was supported by Coutsoudis ${ }^{20}$.

Malnutrition is an important factor that affects vitamin A status as was reported earlier ${ }^{21}$. Mahalanabis ${ }^{22}$ had observed that in addition to the severe PEM and poor socioeconomic status, recent measles, prolonged diarrhea are also important risk factors or prognostic indicators for exophthalmia.

All the students from low socioeconomic class have signs of VAD. This goes with the WHO/UNICEF report in $2004^{5}$.

Our finding of signs of VAD in $72.2 \%$ of those who were infected supports the suggestions that there is a close association between vitamin A deficiency and infections. ${ }^{23}$

$\mathrm{VAD}$ is a major nutritional problem among Khalwa student since $51.7 \%$ had signs of VAD (Figure 3$)^{18}$.

Significant increase was recorded in the mean serum retinol after supplementation (from $32.42 \pm 15.43 \mu \mathrm{g} / \mathrm{dl}$ to $49.1 \pm 12.2 \mu \mathrm{g} / \mathrm{dl})$. An 
adequate level was reported by most of the students $(76.7 \%)$, while $20.0 \%$ had marginal status, and only one $(3.3 \%)$ was deficient. Similar results were obtained by others ${ }^{24-26}$.

There was a significant increase in the mean RBP after sugar fortification.

A similar result was obtained by Bloem et $\mathrm{al}^{27}$. This increase in RBP might be explained by the fact that increased pool of native apoprotein accumulates in the liver during VAD which is released to the plasma quickly after retinol uptake resulting in increased RBP level ${ }^{28}$.

\section{Conclusion:}

Sugar fortification with vitamin A resulted in significant improvement of Vitamin A status in our patients. This method can be applied nationally as a strategic interventional program to reduce the high risk of Vitamin A Deficiency.

Acknowledgement: We are very grateful to University of Khartoum and the Gordon Memorial College Trust Fund for funding our study.

\section{References:}

1. MI/HKI. Integrating vitamin supplementation into CDTI: The Experience of Hellen Keller International and the Micronutrient Initiative, 2004. Washington DC, USA.

2. WHO/EMRO. Towards a National Nutrition Policy. Health Organization /Eastern Mediterranean Region Office Technical report series no. 17 1990, Alexandria.Egypt.

3. HKI. Bellagio Meeting on Vitamin A Deficiency and Childhood Mortality. HKI-1992, USA.

4. WHO/EMRO, 2004.World Health Organization/ Eastern Mediterranean Region Office, Sudan representative Office. 2004. Available on line from URL : http:// www.emro.whoint/sudan/.

5. WHO/UNICEF. Sudan immunization profile, Joint report of World Health Organization and UNICEF, 2004.

6. ND/FMOH. National immunization days (NIDs). NIDs coverage report, Nutrition Department, Federal Ministry of Health, December 2005.

7. Doris C, Vilma E, Hilda M. Ten Years after intervention? : achievements, and Challenges [abstract]. In Report of the XVIII International Vitamin A Consultative Group Meeting. Cairo, Egypt; 1999: Sustainable control of Vitamin A Deficiency: Defining Progress through Assessment Surveillance, Evaluation. Washington DC: IVACG, 1988:88.

8. Mora JO, Dary P. Vitamin A sugar fortification in Central America: experiences and Lessons learned $2000 . \quad$ Washington DC: MOST/USAIDS/INCAP/PAHO.
9. Nestel P and Nalubola R. Food Fortification is an effective public health intervention article USAID.ILSI, January 2003,USA.

10. WHO/IVACG. XVII IVACG Meeting 1996, Guatemala.

11. Passmore R, Eastwood MA. Human Nutrition and Dietetics $\left(8^{\text {th }}\right.$ edition)(ELBS)\&Churchill 1996- U.K.

12. WHO. Measuring change in nutritional status. World Health Organisation WHO 1983, Geneva.

13. Bieri JG, Tolliver TJ, Catignani GL. Simultaneous Determination of Retinol and Tochopherol in plasma or red cells by high pressure liquid chromatography. Am. J. Clin. Nutr. 1979; 32, 2143-2149.

14. Macini G, Carbonara AO. Immunochemical Quantitation of Antigens by Single Radial Immunodiffusion, Immunchem. 1965; 2, 235-254.

15. Flores H, Camposs F, Araujo RC, Underwood B. Assessment of vitamin A deficiency in Brazilian children using the relative dose response procedure. Am J. Clin. Nutr., 1984 Dec.; 40(6), 1281-1289.

16. Underwood B A Methods of Assessment of Vitamin A Status, J. Nutrition 1990 . 120,1459-1463.

17. WHO/UNICEF Indicators for Assessing Vitamin A Deficiency and their Application in Monitoring and Evaluating Intervention Programs; Joint Report of WHO/UNICEF, 1994. Geneva, Switzerland.

18. WHO. Control of Vitamin A deficiency and Xerophthalmia. World Health Organisation Technical report no. 672, 1982. WHO, Geneva.

19. Mamoun N, Homedia S, Mabyou M et al.

Prevalence, Types and Risk Factors for Malnutrition in Displaced Sudanese Children. Am. J. Inf. Dis. 2005; 1 (2): 84-86.

20. Coutsoudis A, Zwane M, Coovadia HM, Gouws E. Dietary intake of vitamin A in African preschool children in Umlazi, South Africa. Int. J. Vitam. Nutr 1992; Res. 63(1), 3

21. Buyukgebiz B, Ozalp I, Oran O. Investigation of serum vitamin A levels of children who had a history of recurrent diarrhoea and acute respiratory tract infection in Ankara. J.Trop. Pediatr. 1990; 36 (5), 251-5.

22. Mahalanabis D. Breast feeding and vitamin A deficiency among children attending a diarrhoea treatment centre in Bangladesh; a case-control study .B.M.J. 1991; 303(6801), 493-496.

23. Sommer A. A Field Guide to Detection of and Control of Xerophthalmia (2nd edition)WHO1982, Geneva.

24. van Jaarsveld PJ, Faber M, Tanumihardjo SA, Nestel P, Lombard CJ , Benade AJS. $\beta$-carotene-rich orange-fleshed sweetpotato (OFSP) improves VA status of school children assessed with the modified relative-dose-response test. Am. J Clin.Nut 2005; 81, 1080-1087.

25. Muhilal AM, Permeisih D, Idjraddinata $Y$ R, Muherdiyantiningsih, Karyadi D. Vitamin fortified monosodium glutamate and health, growth and survival of children: A controlled field trial. Am. J. Clin. Nutr. 1988; 48,1271-1276.

26. Schubarth P. Vitamin A deficiency in developing countries,Ther-Umsch 1994.; 51(7),510-516. 


\section{Shommo SAM}

27. Bloem MW, Wedel M, van-Agtmaal EJ, Speek AJ, Saowakontha S, Schreurs WHP. Vitamin A Intervention :Short Term Effect of single, Oral Massive dose on Iron Metabolism. Am. J. Clin. Nutr. 1990; 51(1): 76-9.
Effect of sugar fortification with vitamin A on serum retinol

28. Large S, Neal G, and Glover J. The early childhood changes in retinol binding protein and prealbumin concentration in plasma of protein-energy malnourished children after treatment with retinol and improved diet. Br J Nutr. 1980; 43: 393-402. 